\title{
Factors associated with Empathy in Patients with Schizophrenia in Psychiatric Rehabilitation Centers
}

\author{
Song, Eun Ju \\ Associate Professor, Department of Nursing, Wonkwang University, Iksan, Korea
}

\begin{abstract}
Purpose: Empathy is the most important communication skill, and patients with schizophrenia in recovery should be taught empathy for vocational rehabilitation and social life. The purpose of this study was to investigate factors affecting empathy, as well as motivation-pleasure and social anhedonia, in patients with schizophrenia in psychiatric rehabilitation. Methods: This study followed a descriptive design using a cross-sectional survey to assess the empathy, social anhedonia, and motivation-pleasure levels of patients with schizophrenia. The participants were 118 patients with schizophrenia from five mental health rehabilitation centers in South Korea. Results: The results of this study show a high correlation among empathy, motivation-pleasure, and social anhedonia. The variables affecting empathy were age, motivation-pleasure, and social anhedonia, and the explanatory power of the variables was $32.6 \%$. Conclusion: The results of this study suggest that improving communication skills and negative symptoms will contribute positively to patients' social lives and vocational rehabilitation.

Key Words: Anhedonia; Empathy; Motivation; Pleasure; Schizophrenia
\end{abstract}

\section{INTRODUCTION}

\section{Background}

The lifetime prevalence of schizophrenia is reported as approximately $1 \%$ worldwide and $0.4 \sim 0.7 \%$ in Korea [1]. Although occupational rehabilitation is an effective treatment for the recovery of schizophrenia, patient's employment rate is considerably low at $18.4 \%$ [2]. The main goal for the recovery of patients with schizophrenia is often vocational rehabilitation to gain competitive employment [3].

Good communication skills and positive interpersonal relations have more impact on the employment potential of patients with schizophrenia than symptoms of schizophrenia psychopathology [2,4]. These patients struggle with understanding others and establishing interpersonal relationships due to low empathy, resulting in challenges in completing job activities [3,4]. Bonfils and his colleagues found that patients with schizophrenia had difficul- ties in understanding others [5]. Individuals with schizophrenia struggle to process and interpret socioemotional information from others, and within themselves, thus they often experience poor social adjustment [2]. Many patients with schizophrenia participate in social skills training to improve social adjustment and communicate efficiently [4]. It is thus recommended that they are trained to improve their communication skills at the beginning of their vocational rehabilitation.

In clinical practice, empathy is a critical factor for successful recovery, and its assessment can help in the development of suitable nursing interventions [6,7]. To improve empathic process in patients with schizophrenia, several types of interventions such as cognitive-behavioral therapy, empathy training programs, and interpersonal skills training are recommended. However, previous studies suggest the development of more specific interventions is still limited for patients with schizophrenia [5,7]. Therefore, promoting empathy should be emphasized in the re-

\footnotetext{
Corresponding author: Song, Eun Ju https://orcid.org/0000-0003-1894-8759

Department of Nursing, Wonkwang University, 460 Iksan-daero, Iksan 54538, Korea.

Tel: +82-63-850-6013, Fax: +82-63-850-6060, E-mail: chanjun@wku.ac.kr

- This research was supported by the National Research Foundation of Korea (NRF) funded by the Korean government (NRF-2018R1D1A1B07043235).

- This study was approved by the institutional review board of Wonkwang university hospital (approval no.: WKUH 2018-11-001-001).

Received: Jan 8, 2020 | Revised: Feb 17, 2020 | Accepted: Mar 21, 2020
}

This is an open access article distributed under the terms of the Creative Commons Attribution Non-Commercial License (http://creativecommons.org/licenses/ by-nc/3.0), which permits unrestricted non-commercial use, distribution, and reproduction in any medium, provided the original work is properly cited. 
habilitation stage to develop and implement interventions that also help in treating negative symptoms.

Psychosocial rehabilitation is an essential factor in the standard care of patients with chronic schizophrenia [4], where various programs and therapies are combined with pharmacological treatment. Antipsychotics alleviate positive symptoms such as hallucinations and delusions, but do not significantly impact negative symptoms such as diminished expression and motivation [8]. In particular, negative symptoms are considered as the fundamental reason behind patients with schizophrenia having a low employment rate as their daily life is affected [9]. Their work life is unstable due to a lack of motivation and pleasure, and social anhedonia [1]. Lack of motivation and pleasure at the workplace is an important negative symptom as it indicates low effort or motivation to participate in social and occupational activities [10]. In practice, patients can participate in rehabilitation activities even if they have negative symptoms, where they will experience therapeutic challenges [4]. Patients with schizophrenia are unable to maintain a job for more than six months, due to a lack of motivation [2]. Thus, the management of this particular symptom could contribute to successful long-term employment.

Social anhedonia is a frequently used term for patients with or without schizophrenia [11]. Social anhedonia is related to a lack of social enjoyment and interest, which results in limited experiences of interpersonal relationships or friendships with significant others [12]. It occurs at any stage of this disease, either early on or during chronic periods of the illness, and gets worse when patients do not receive therapeutic intervention and medical attention [13, 14]. To achieve successful vocational rehabilitation, social anhedonia in patients which may lead to avoidance of social situations $[2,4]$, should be the focus of improvement. In a recent study, anhedonia was identified as an essential factor contributing to the health-related quality of life of patients with schizophrenia [15]. Therefore, understanding the influence of empathy according to social anhedonia level will help in the improvement of rehabilitation programs. The management of this symptom may be essential for patients preparing for vocational rehabilitation. Thus, the purpose of this study was to investigate factors that associate with empathy in patients with schizophrenia in psychiatric rehabilitation.

\section{METHODS}

\section{Design}

This study was descriptive and cross-sectional in design using survey.

\section{Participants}

Study participants were patients with schizophrenia selected from five mental health rehabilitation centers located in one province of South Korea. A convenience sampling method was used with the eligibility criteria that: (1) patients were between 19 and 60 years old; (2) patients understood the purpose of the study and voluntarily agreed to participate ; and (3) patients were diagnosed with schizophrenia or had a schizoaffective diagnosis based on the DSM-5 criteria.

A total of 140 questionnaires were distributed and data from 118 participants were analyzed after excluding incomplete data. This final sample met the required sample size for multiple linear regression, 90, with the following parameters: 18 independent variables, a power of 0.95 , an $\alpha$ of 0.05 , and an effect size of 0.15 based on sample size calculation with $\mathrm{G}^{*}$ Power v. 3.1 (Heinrich Heine University, Dusseldorf, Germany).

\section{Ethical Considerations}

The institutional review board approved this study of Wonkwang university hospital (approval no.: WKUH 201811-001-001). The researcher explained the study purpose to each agency administrator and obtained their permission. The researcher explained the purpose of this study to the patients who met the eligibility criteria, and they were informed that participation was voluntary and that they could withdraw at any time. After informed consent was obtained from each participants, participants responded to the questionnaires by themselves.

\section{Measurements}

\section{1) Interpersonal Reactivity Index (IRI)}

The IRI was developed by Davis [16] and is the most widely used self-reported scale for affective empathy [5, 17]. This scale is used to study psychiatric disorders in patients with an empathy deficit or disturbance [6]. The IRI consists of 28 items rated on a 5-point Likert scale (0 4), and total scores range from 0 to 112 with higher scores reflecting higher levels of empathy. Criterion-related validity was evaluated by examining correlations between the IRI and affective dimension scale $(\mathrm{r}=.31, p<.05)$ [6]. The Cronbach's $\alpha$ in David's [16] study was .70 .78, .72 .79 in Lucas-Molina et al. [17], and .76 in Kang et al. [6], while it was .72 in this study. 


\section{2) Motivation and Pleasure Scale-Self-Report (MAP-SR)}

The MAP-SR consists of 15 items extracted from the CAINS (Clinical Assessment Interview for Negative Symptoms) motivation and pleasure subscale [18]. This scale evaluates asociality, amotivation, blunted affect, and alogia. All items are rated on a 5-point Likert scale $(0 \sim 4)$; the total scores range from 0 to 60 ; higher ratings mean more significant pathology after all items are reverse scored [10]. Criterion-related validity was evaluated by examining correlations between the MAP-SR and BPRS ( $\mathrm{r}=.41, p=.011)$ [9]. Cronbach's $\alpha$ was .88 in Engel and Lincoln's [10] study and .90 in this study.

\section{3) Revised Social Anhedonia Scale (RSAS)}

The RSAS is composed of 40 items in a true/false format measuring schizoid indifference, associability, decreased pleasure in the social domain, and indifference toward others. The RSAS assesses deficits in the ability to experience joy from non- physical stimuli such as other people, talking, and exchanging expressions of feelings [19]. The total scores range from 0 to 40 ; higher scores are associated with greater degrees of anhedonia. Criterionrelated validity was evaluated by examining correlations between social anhedonia and social relationships $(r=-.43$, $p<.001$ ) [15]. The Cronbach's $\alpha$ was .86 in the previous study [20] and .81 in this study.

\section{Data Collection and Analysis}

The data were collected from November to December 2018. The researcher provided sufficient time for questionnaire completion (approximately 20 minutes). All data were analyzed using IBM SPSS Statistics for Windows v. 24.0 (IBM Corporation, Armonk, NY, USA). The procedure for data analysis was as follows: (1) the general characteristics of the participants were calculated as frequencies and percentages; (2) differences in the general characteristics were examined using independent t-tests and one-way analysis of variance with Scheffé test; (3) Pearson's correlation coefficients were examined to explore the relationships among empathy, motivation-pleasure, and social anhedonia; and (4) hierarchical regression analysis was conducted to determine association of empathy.

\section{RESULTS}

\section{Demographic Characteristics}

Surveys from 77 men (65.3\%) and 41 women (34.7\%) were identified. The age groups were 20 to 39 years (24.6
$\%), 40$ to 49 years $(33.9 \%)$, and over 50 years $(41.5 \%)$. The highest level of education for most participants was high school completion (54.2\%). A total of 42 participants lived in residential facilities (35.6\%), 41 participants lived with family (34.8\%), and 24 participants lived alone (20.3\%). Forty participants were employed (33.9) and seventy-eight were unemployed $(66.1 \%)$. In terms of the duration of schizophrenia diagnosis, 25 participants were diagnosed less than ten years ago (21.1\%), 39 participants were diagnosed between 11 and 20 years ago (33.1\%), and 54 participants were diagnosed over 21 years ago $(45.8 \%)$.

Eighty-four $(71.2 \%)$ participants participated in a communication program, while 34 participants $(28.8 \%)$ did not take part in the program. Most of the participants (86.4\%) thought that communication programs are necessary and helpful. Thirty-two participants responded that they communicate best with their parents $(27.1 \%)$, followed by friends (17.8\%), colleagues (14.4\%), and doctors (13.6 $\%)$. Twenty-three participants replied that they communicated poorly with colleagues (19.5\%), followed by parents (18.6\%), siblings $(17.9 \%)$, and doctors $(12.7 \%)$. Further details on the patients' general characteristics are presented in Table 1.

\section{Levels of and Differences in the IRI, the MAP-SR, and the RSAS scores by General Characteristics}

The mean scores for the variables were as follows: IRI, 59.49 \pm 2.12; MAP-SR, 23.49 \pm 13.18 ; and RSAS, $14.35 \pm 6.36$ (Table 2). The IRI scores significantly differed by age groups $(\mathrm{t}=5.09, p=.008)$ and the need for communication intervention $(t=2.19, p=.030)$. The employment group had lower MAP-SR scores than the unemployed group $(t=-1.99, p=$ .048). Participants who had participated in a communication program had lower MAP-SR scores than those who did not $(t=-2.96, p=.004)$, and participants who needed the communication program had lower MAP-SR scores than those who did not $(t=-4.36, p<.001)$. For RSAS scores, a significant difference was identified in the need for a communication program $(\mathrm{t}=0.24, p=.011)$. Further details about the variable means and differences according to the general characteristics are presented in Table 3.

\section{Correlations among IRI, MAP-SR, and RSAS scores}

IRI scores significantly and positively correlated with MAP-SR scores $(r=.48, p<.001)$, while IRI scores showed a significantly negative relationship with RSAS scores $(\mathrm{r}=-.41, p<.001)$. The MAP-SR scores positively correlated with those on the RSAS ( $r=.50, p<.001$; seen in Table 4$)$. 
Table 1. General Characteristics of Participants

$(N=118)$

\begin{tabular}{|c|c|c|}
\hline Characteristics & Categories & $\mathrm{n}(\%)$ \\
\hline \multirow[t]{2}{*}{ Gender } & Men & $77(65.3)$ \\
\hline & Women & $41(34.7)$ \\
\hline \multirow[t]{3}{*}{ Age (year) } & $20 \sim 39$ & $29(24.6)$ \\
\hline & $40 \sim 49$ & $40(33.9)$ \\
\hline & $50 \sim 60$ & $49(41.5)$ \\
\hline \multirow[t]{3}{*}{ Education } & Middle school & $17(14.4)$ \\
\hline & High school & $64(54.2)$ \\
\hline & Over College & $37(31.4)$ \\
\hline \multirow[t]{4}{*}{ Residential situation } & Residential facility & $42(35.6)$ \\
\hline & Family & 41 (34.8) \\
\hline & Alone & $24(20.3)$ \\
\hline & Friend(s) & $11(9.3)$ \\
\hline \multirow[t]{2}{*}{ Employment } & Employed & $40(33.9)$ \\
\hline & Unemployed & $78(66.1)$ \\
\hline \multirow{3}{*}{$\begin{array}{l}\text { Duration of schizophrenia } \\
\text { diagnosis (year) }\end{array}$} & $\leq 10$ & $25(21.1)$ \\
\hline & 11 20 & 39 (33.1) \\
\hline & $\geq 21$ & $54(45.8)$ \\
\hline \multirow{3}{*}{$\begin{array}{l}\text { Duration of center use } \\
\text { (year) }\end{array}$} & $\leq 5$ & $64(54.2)$ \\
\hline & $6 \sim 10$ & $29(24.6)$ \\
\hline & $\geq 11$ & $25(21.2)$ \\
\hline \multirow{2}{*}{$\begin{array}{l}\text { Participation in } \\
\text { communication program? }\end{array}$} & Yes & $84(71.2)$ \\
\hline & No & $34(28.8)$ \\
\hline \multirow{2}{*}{$\begin{array}{l}\text { Need for a communication } \\
\text { program? }\end{array}$} & Necessary & $102(86.4)$ \\
\hline & Unnecessary & $16(13.6)$ \\
\hline \multirow{7}{*}{$\begin{array}{l}\text { A person who } \\
\text { communicates well with } \\
\text { the patient }\end{array}$} & Parents & $32(27.1)$ \\
\hline & Friends & $21(17.8)$ \\
\hline & Patient's colleagues & $17(14.4)$ \\
\hline & Doctors & 16 (13.6) \\
\hline & Siblings & $11(9.3)$ \\
\hline & Nurses & $10(8.5)$ \\
\hline & Other & $11(9.3)$ \\
\hline \multirow{7}{*}{$\begin{array}{l}\text { A person having difficulty } \\
\text { communicating with a } \\
\text { patient }\end{array}$} & Patient's colleagues & $23(19.5)$ \\
\hline & Parents & $22(18.6)$ \\
\hline & Siblings & $21(17.9)$ \\
\hline & Doctors & 15 (12.7) \\
\hline & Nurses & $6(5.1)$ \\
\hline & Friends & $5(4.2)$ \\
\hline & Other & $26(22.0)$ \\
\hline
\end{tabular}

Table 2. Levels of IRI, MAP, and Social Anhedonia $(N=118)$

\begin{tabular}{ll}
\hline Variables & $\mathrm{M} \pm \mathrm{SD}$ \\
\hline IRI & $59.49 \pm 2.12$ \\
MAP & $23.49 \pm 13.18$ \\
Social anhedonia & $14.35 \pm 6.36$ \\
\hline
\end{tabular}

IRI=Interpersonal Reactivity Index; MAP=Motivation and Pleasure Scale.

\section{Factors associated with Self-esteem}

A hierarchical linear regression analysis was applied to identify the variables affecting empathy. The general characteristic variables of age, employment, participation in communication intervention, and the need for communication intervention were recoded as dichotomized variables. Then, the MAP-SR and RSAS variables were entered as hierarchical input. To examine autocorrelation, the Durbin-Watson statistic was 2.04, which was close to 2. Furthermore, tolerance ranged from .80 to .98 , and the variance inflation factor ranged from 1.02 to 1.16 , that indicated no concern on multicollinearity.

Age, employment, participation in a communication program, and the need for education or the intervention of a communication program were included in Model I in the hierarchical regression analysis. Age $(\beta=-.28, p=.002)$ was a significant factor of empathy, with an explanatory power of $14.6 \%$. Scores on the MAP-SR $(\beta=-.32, p=.001)$ and the RSAS ( $\beta=-.21, p=.020)$ were found to have an explanatory power of $18.0 \%$ in Model II. The total explanatory power of these factors was $32.6 \%(\mathrm{~F}=14.80, p<.001)$. Further details on the model of empathy are presented in Table 5.

\section{DISCUSSION}

This study examined correlations among empathy, motivation-pleasure, and social anhedonia, and then identified the significant factors associated with empathy in psychiatric rehabilitation in patients with schizophrenia. This study identified that empathy had a positive correlation with motivation-pleasure, while it had a negative correlation with social anhedonia. Specific factors associated with empathy were age, motivation-pleasure, and social anhedonia.

In this study, participants were mostly able to communicate with their parents, whereas parents perceived that they were not unable to communicate with the patient. Generally, most studies on schizophrenia communication tend to focus on neurocognitive functions or social cognition $[14,21]$. In the literature on schizophrenia, very few studies have analyzed the impact of specific communication on the daily life and relationships of real-world functioning patients with schizophrenia [22]. Although 71.2\% of the participants had experienced communication interventions, $86.4 \%$ of the participants responded to the need for a communication intervention in this study. Patients using rehabilitation centers may have attended communication programs since their hospitalization. Nevertheless, more than $80 \%$ of patients replied that intervention is re- 
Table 3. Analysis of Differences in IRI, MAP, and Social Anhedonia by General Characteristics

$(N=118)$

\begin{tabular}{|c|c|c|c|c|c|c|c|}
\hline \multirow{2}{*}{ Variables } & \multirow{2}{*}{ Categories } & \multicolumn{2}{|c|}{ IRI } & \multicolumn{2}{|c|}{ MAP } & \multicolumn{2}{|c|}{ Social anhedonia } \\
\hline & & $\mathrm{M} \pm \mathrm{SD}$ & t or F $(p)$ & $\mathrm{M} \pm \mathrm{SD}$ & t or F $(p)$ & $\mathrm{M} \pm \mathrm{SD}$ & t or $F(p)$ \\
\hline \multirow[t]{2}{*}{ Gender } & Men & $59.00 \pm 11.11$ & \multirow[t]{2}{*}{$-0.73(.464)$} & $24.58 \pm 13.41$ & \multirow[t]{2}{*}{$1.23(.219)$} & $14.99 \pm 6.32$ & \multirow[t]{2}{*}{$1.50(.135)$} \\
\hline & Women & $60.41 \pm 7.25$ & & $21.44 \pm 12.66$ & & $13.15 \pm 6.34$ & \\
\hline \multirow[t]{3}{*}{ Age (year) } & $20 \sim 39^{\mathrm{a}}$ & $54.66 \pm 10.44$ & \multirow[t]{3}{*}{$5.09(.008)$} & $25.66 \pm 12.58$ & \multirow[t]{3}{*}{$0.54(.584)$} & $15.97 \pm 6.76$ & \multirow[t]{3}{*}{$1.30(.274)$} \\
\hline & $40 \sim 49^{\mathrm{b}}$ & $61.80 \pm 10.81$ & & $22.43 \pm 14.13$ & & $14.08 \pm 6.18$ & \\
\hline & $50 \sim 60^{c}$ & $60.47 \pm 7.89$ & & $23.08 \pm 12.86$ & & $13.61 \pm 6.23$ & \\
\hline \multirow[t]{3}{*}{ Education } & Middle school & $58.94 \pm 8.28$ & \multirow[t]{3}{*}{$0.84(.433)$} & $24.94 \pm 16.37$ & \multirow[t]{3}{*}{$2.38(.097)$} & $14.29 \pm 5.65$ & \multirow[t]{3}{*}{$1.93(.149)$} \\
\hline & High school & $58.63 \pm 10.01$ & & $25.34 \pm 11.92$ & & $15.30 \pm 6.59$ & \\
\hline & Postschool & $61.24 \pm 10.48$ & & $19.62 \pm 13.21$ & & $12.73 \pm 6.08$ & \\
\hline \multirow{4}{*}{$\begin{array}{l}\text { Residential } \\
\text { situation }\end{array}$} & Family & $58.61 \pm 12.09$ & \multirow[t]{4}{*}{$0.28(.837)$} & $25.02 \pm 15.09$ & \multirow[t]{4}{*}{$0.57(.632)$} & $15.90 \pm 6.15$ & \multirow[t]{4}{*}{$1.40(.244)$} \\
\hline & Friend & $58.27 \pm 8.24$ & & $22.91 \pm 13.38$ & & $12.91 \pm 6.38$ & \\
\hline & Single & $60.25 \pm 9.17$ & & $24.67 \pm 12.97$ & & $13.04 \pm 6.21$ & \\
\hline & Residential facility & $60.24 \pm 8.54$ & & $21.48 \pm 11.33$ & & $13.95 \pm 6.56$ & \\
\hline \multirow[t]{2}{*}{ Employment } & Yes & $61.13 \pm 9.39$ & \multirow[t]{2}{*}{$1.28(.202)$} & $20.15 \pm 12.24$ & \multirow[t]{2}{*}{$-1.99(.048)$} & $12.95 \pm 6.11$ & \multirow[t]{2}{*}{$-1.72(.088)$} \\
\hline & No & $58.65 \pm 10.15$ & & $25.21 \pm 13.40$ & & $15.06 \pm 6.41$ & \\
\hline \multirow{3}{*}{$\begin{array}{l}\text { Duration of } \\
\text { schizophrenia } \\
\text { diagnosis (year) }\end{array}$} & $\leq 10$ & $60.96 \pm 12.23$ & \multirow[t]{3}{*}{$1.20(.303)$} & $22.84 \pm 12.28$ & \multirow[t]{3}{*}{$1.86(.160)$} & $15.32 \pm 7.02$ & \multirow[t]{3}{*}{$1.73(.181)$} \\
\hline & $11 \sim 20$ & $57.51 \pm 9.96$ & & $26.72 \pm 15.18$ & & $15.36 \pm 5.92$ & \\
\hline & $\geq 21$ & $60.24 \pm 8.62$ & & $21.43 \pm 11.76$ & & $13.17 \pm 6.28$ & \\
\hline \multirow{3}{*}{$\begin{array}{l}\text { Duration of center } \\
\text { use (year) }\end{array}$} & $\leq 5$ & $58.55 \pm 11.15$ & \multirow[t]{3}{*}{$0.87(.421)$} & $25.33 \pm 13.93$ & \multirow[t]{3}{*}{$1.44(.240)$} & $14.13 \pm 6.15$ & $0.49(.609)$ \\
\hline & $6 \sim 10$ & $61.48 \pm 7.93$ & & $21.97 \pm 1078$ & & $15.34 \pm 6.55$ & \\
\hline & $\geq 11$ & $59.60 \pm 8.59$ & & $20.56 \pm 13.49$ & & $13.76 \pm 6.81$ & \\
\hline Participation in & Yes & $60.54 \pm 9.39$ & $1.81(.072)$ & $21.27 \pm 11.99$ & $-2.96(.004)$ & $14.14 \pm 6.25$ & $-0.54(.585)$ \\
\hline $\begin{array}{l}\text { communication } \\
\text { program }\end{array}$ & No & $56.91 \pm 10.86$ & & $28.97 \pm 14.54$ & & $14.85 \pm 6.71$ & \\
\hline Need for & Necessary & $60.27 \pm 9.68$ & $2.19(.030)$ & $21.54 \pm 12.13$ & $-4.36(<.001)$ & $13.76 \pm 6.39$ & $0.24(.011)$ \\
\hline $\begin{array}{l}\text { communication } \\
\text { intervention }\end{array}$ & Unnecessary & $54.50 \pm 10.35$ & & $35.94 \pm 13.21$ & & $18.06 \pm 4.89$ & \\
\hline
\end{tabular}

IRI=Interpersonal Reactivity Index; MAP=Motivation and Pleasure Scale.

Table 4. Correlations among IRI, MAP, and Social Anhedonia

\begin{tabular}{|c|c|c|c|}
\hline \multirow{2}{*}{ Variables } & IRI & MAP & Social anhedonia \\
\hline & $\mathrm{r}(p)$ & $\mathrm{r}(p)$ & $r(p)$ \\
\hline IRI & 1 & & \\
\hline MAP & $.48(<.001)$ & 1 & \\
\hline Social anhedonia & $-.41(<.001)$ & $.50(<.001)$ & 1 \\
\hline
\end{tabular}

$\mathrm{IR}=$ Interpersonal Reactivity Index; MAP=Motivation and Pleasure Scale.

quired regardless of the previous experience of the communication program. This result indicates that they would benefit from sessions with a mental health professional to discuss communication problems. Based on these results, it is necessary to conduct further research on these episodes to develop various scenarios to use for training purposes in communication education programs for patients in the dynamics of real-world communication.

Younger patients had lower IRI scores, which meant low empathic capacity. This finding indicates that communication intervention should be initiated early in the onset of schizophrenia or for young patients with schizophrenia to improve empathy. Considering early development of the brain, a young person's speech can help predict the future development of psychosis later in life, suggesting a link between communication and schizophrenia [21]. Therefore, communication intervention can be provided at an earlier stage to prevent social regression. The 
Table 5. Factors associated with Empathy

$(N=118)$

\begin{tabular}{|c|c|c|c|c|c|c|c|c|}
\hline \multirow{2}{*}{ Variables } & \multicolumn{4}{|c|}{ Model I } & \multicolumn{4}{|c|}{ Model II } \\
\hline & B & $\beta$ & $\mathrm{t}$ & $p$ & B & $\beta$ & $\mathrm{t}$ & $p$ \\
\hline (Constant) & 54.00 & & 20.83 & $<.001$ & 69.68 & & 18.74 & $<.001$ \\
\hline $\operatorname{Age}^{\dagger}$ ( $\geq 40$ years $)$ & -6.50 & -.28 & -3.24 & .002 & -5.08 & -.22 & -2.79 & .006 \\
\hline Employment $^{\dagger}$ (no) & 1.32 & .06 & .71 & .474 & 0.07 & $<.01$ & 0.04 & .965 \\
\hline Experienced communication intervention $^{\dagger}$ (no) & 4.81 & .16 & 1.81 & .072 & 1.73 & .08 & 0.97 & .332 \\
\hline Need for communication intervention ${ }^{\dagger}$ (unnecessary) & 4.81 & .16 & 1.87 & .064 & 0.45 & .01 & 0.18 & .854 \\
\hline MAP & & & & & -0.24 & -.32 & -3.31 & .001 \\
\hline \multirow[t]{2}{*}{ Social anhedonia } & & & & & -0.33 & -.21 & -2.36 & .020 \\
\hline & \multicolumn{4}{|c|}{$\begin{array}{c}\mathrm{R}^{2}=.14, \text { Adjusted } \mathrm{R}^{2}=.11 \\
\mathrm{~F}=4.84, p=.001\end{array}$} & \multicolumn{4}{|c|}{$\begin{array}{c}\mathrm{R}^{2}=.32, \Delta \mathrm{R}^{2}=(.18), \text { Adjusted } \mathrm{R}^{2}=.29, \\
\mathrm{~F}=14.80, p<.001\end{array}$} \\
\hline
\end{tabular}

${ }^{\dagger}$ Dummy variables had the followed reference group: Age (20 39 years=0); Employment (yes=0); Experienced communication intervention (yes=0); Need for communication intervention (necessary $=0$ ).

IRI scores of subjects who did not express a need for a communication program were significantly low. This group composed of less number of people (16 participants). Although they may have participated in communication interventions, these programs did not have a major effect on them in the past. It is also possible that these responses emerged in this group due to negative symptoms. Empathy and negative symptoms can be improved through educational or training programs [4,7].

Mental health professionals should encourage individuals to participate in various activities. In this study, the mean IRI score was 59.49 points lower than those of the general population [23]. Still, it was similar to the previous study on outpatients with schizophrenia [14]. In a study by Chiang et al.[24], the level of empathy in patients with schizophrenia was over 64 points, indicating that environmental differences affected levels of empathy in the ward, for outpatients, and centers. Since previous studies have measured levels of empathy in a specific setting, this researcher recommends that further studies should be conducted with different subjects in various environments using a cross-sectional method. In general, women have significantly higher IRI scores than men in the general population [23]; gender being the important factor [5,17]. However, there were no gender differences in this study.

In this study, the MAP-SR score of 23.49 reflected greater stability than the score of 25.93 among patients with acute schizophrenia [10]. However, more significant differences were evident when these scores were compared with the score of 17.1 in people without schizophrenia [25]. Employed subjects had a significantly better MAP-SR score than unemployed participants. The MAP-SR score was significantly higher in subjects who had taken part in a communication program and those who felt that a communication program was necessary. Patients with schizophrenia who had experienced vocational rehabilitation, employment, longer work hours per week, and a higher income were reported to have better planning, reasoning, and problem-solving abilities [3]. Therefore, vocational rehabilitation can improve not only the symptoms but also the intellectual and rational skills of patients with schizophrenia. In this study, the IRI showed higher scores for participants who were employed than those who were unemployed. Communication interventions also correlated with more work hours per week and a higher income [3]. Pleasure and motivation in one's daily life and the opportunity to earn money by completing a task within one's skill set is a uniquely rewarding experience for the effort put in to do a challenging task [26]. Employment is a central and vital goal for the recovery of patients with schizophrenia $[2,3]$. Thus, being employed with schizophrenia can be regarded as an important index, and the improvement in negative symptoms can contribute to the overall quality of life. Although deinstitutionalization rate has increased due to drug development, the employment rate of patients with schizophrenia is still low [2]. Mental health professionals should actively participate in the resolution of this issue, and an employment friendly national policy such as a mandatory employment system for the disabled should be paralleled together. To this end, nursing interventions in rehabilitation centers will need to focus on employment rates.

In this study, the level of social anhedonia in subjects was higher than that in people without schizophrenia [21]. 
Nonetheless, it was similar to the levels observed in patients with schizophrenia in previous studies [27]. Besides, the social anhedonia scores of the subjects who responded to the need for communication education were significantly better, which suggests a high level of willingness to engage in training that may increase rehabilitation abilities. Improvements in social anhedonia have a positive impact on symptom management because it is relatively independent of psychotic and depressive symptoms [28]. Although social anhedonia is associated with compensation such as money [26], there was no difference between employed patients and unemployed people in this study.

The positive correlation between empathy and motivation-pleasure was significantly higher. This finding indicates that empathy can be improved when motivationpleasure symptoms are improved. Additionally, empathy showed a significantly negative correlation with social anhedonia. Social anhedonia reported a negative association with positive concepts [21]. This study supports that social anhedonia negatively correlates with the positive variables such as the interpersonal pleasure in the previous research [21]. Motivation-pleasure and social anhedonia were negatively correlated, which is consistent with a previous study [18]. Although negative symptoms such as anhedonia were thought to involve difficulties with motivation, more significant negative symptoms were associated with more effort in decision making in individuals with schizophrenia [26]. The motivation-pleasure and social anhedonia of the patients with chronic schizophrenia could be improved through training [13]. Future empathy empowerment programs should include a negative symptom training program.

Our study findings showed a high correlation between empathy, motivation, pleasure, and social anhedonia. The variables affecting empathy were age, motivation-pleasure, and social anhedonia with $32.6 \%$ of explanatory power. This study partially supports that a significant negative association between negative symptoms and social functioning was reported [5]. Psychiatric rehabilitation involves social recovery, which increases the level of functioning among patients with schizophrenia [3,5]. Mental health practitioners need to consider interventions that improve the rehabilitation of patients with schizophrenia in reallife scenarios. Communication intervention for patients with schizophrenia after their hospital stay and discharge could provide more comprehensive and practical guidance. Such a program could promote functional recovery, improve negative symptoms, and improve the overall quality of life. Thus, rehabilitation centers for schizophrenia should work together to establish the continuity of a communication intervention.

This study has several limitations. The sample size was small and research was limited to just one province in South Korea. Therefore, it is difficult to generalize our study findings to other groups. In addition, this study focused only on patients who have been in mental health rehabilitation centers. Thus, we suggest that further studies should focus on a more diverse range of clients, such as the patients' colleagues, friends, and family members.

\section{CONCLUSION}

Our study showed that age, employment, communication intervention and the need for communication intervention were factors that affected empathy in patients with schizophrenia in psychiatric rehabilitation. Empathy was related to motivation, pleasure, and social anhedonia. Although many mental health professionals may believe that they are providing various programs to patients with schizophrenia, more than $80 \%$ of patients in this study expressed a need to participate in a communication intervention program. It is necessary to develop proper communication programs and consider their need for timely educational training to maintain their employment capability for rehabilitation.

\section{CONFLICTS OF INTEREST}

The author declared no conflicts of interest.

\section{ORCID}

Song, Eun Ju

https://orcid.org/0000-0003-1894-8759

\section{REFERENCES}

1. Korea Neuropsychiatric Association. Textbook of Neuropsychiatry. 3rd ed. Seoul. IAmIsCompany; 2017. 905 p.

2. Kim HJ, Kim SJ, Kong BG, Kang JW, Moon JJ, Jeon DW, et al. Function and psychosocial factors with occupational rehabilitation in patients with schizophrenia. Journal of the Korean Society of Biological Therapies in Psychiatry, 2014;20(2):142150.

3. Lexén A, Hofgren C, Stenmark R, Bejerholm U. Cognitive functioning and employment among people with schizophrenia in vocational rehabilitation. Work. 2016;54(3):735-744.

https://doi.org/10.3233/WOR-162318

4. Lee HJ, Lee DB, Park MC, Lee SY. The effect of group music therapy on the social function and interpersonal relationship in outpatients with schizophrenia. Journal of Korean Neuropsychiatric Association. 2014;53:40-53. 
https://doi.org/10.4306/jknpa.2014.53.1.40

5. Bonfils KA, Lysaker PH, Minor KS, Salyers MP. Affective empathy in schizophrenia: a meta-analysis. Schizophrenia Research. 2016;175(1-3):109-117.

https://doi.org/10.1016/j.schres.2016.03.037

6. Kang I, Kee SW, Kim SE, Jeong BS, Hwang JH, Song JE, et al. Reliability and validity of the Korean-version of Interpersonal Reactivity Index. Journal of the Korean Neuropsychiatric Association. 2009;48(5):352-358.

7. Jung SJ, Oh SJ. The study on the effect of cognitive-behavioral group art therapy program on the self-esteem and empathy of chronic schizophrenic patients. Journal of Arts Psychotherapy. 2015;11(2):159-178.

8. Remington G, Foussias G, Fervaha G, Agid O, Takeuchi H, Lee $\mathrm{J}$, et al. Treating negative symptoms in schizophrenia: an update. Current Treatment Options in Psychiatry. 2016;3:133-150. https://doi.org/10.1007/s40501-016-0075-8

9. Hyun JW, Woo JM, Jung CH, Kim HC, Kim YT. The relationship between negative symptoms and social cognition in patient with schizophrenia. Journal of the Korean Society of Biological Therapies in Psychiatry. 2016;22(2):84-92.

10. Engel M, Lincoln TM. Motivation and Pleasure Scale-Self-Report (MAP-SR): validation of the German version of a self-report measure for screening negative symptoms in schizophrenia. Comprehensive Psychiatry. 2016;65:110-115. https://doi.org/10.1016/j.comppsych.2015.11.001

11. Cicero DC, Krieg A, Becker TM, Kerns JG. Evidence for the discriminant validity of the Revised Social Anhedonia Scale from social anxiety. Assessment. 2016;23(5):544-556. https://doi.org/10.1177/1073191115590851

12. Chapman JP, Chapman LJ, Kwapil TR. Scales for the measurement of schizotypy. In A. Raine, T. Lencz, \& S. A. Mednick (Eds.), Schizotypical personality. New York, NY: Cambridge University Press; 1995. p. 79-106.

13. Favrod J, Nguyen A, Fankhauser C, Ismailaj A, Hasler J, Ringuet $\mathrm{A}$, et al. Positive emotions program for schizophrenia (PEPS): a pilot intervention to reduce anhedonia and apathy. BMC Psychiatry. 2015;15:231. https://doi.org/10.1186/s12888-015-0610-y

14. Corbera S, Wexler BE, Ikezawa S, Bell MD. Factor structure of social cognition in schizophrenia: is empathy preserved? Schizophrenia Research and Treatment. 2013;ID 409205:1-13. https://doi.org/10.1155/2013/409205

15. Ritsner MS, Arbitman M, Lisker A. Anhedonia is an important factor of health-related quality-of-life deficit in schizophrenia and schizoaffective disorder. The Journal of Nervous and Mental Disease. 2011;199(11):845-853. https://doi.org/10.1097/NMD.0b013e3182349ce6

16. Davis MH. Measuring individual differences in empathy: evidence for a multidimensional approach. Journal of Personality and Social Psychology. 1983;44(1):113-126.

https://doi.org/10.1037/0022-3514.44.1.113

17. Lucas-Molina B, Pérez-Albéniz A, Ortuño-Sierra J, FonsecaPedrero E. Dimensional structure and measurement invariance of the Interpersonal Reactivity Index (IRI) across gender. Psicothema. 2017;29(4):590-595.

https://doi.org/10.7334/psicothema2017.19

18. Llerena K, Park SG, McCarthy JM, Couture SM, Bennett ME, Blanchard JJ. The motivation and pleasure scale-self-report (MAP-SR): reliability and validity of a self-report measure of negative symptoms. Comprehensive Psychiatry. 2013;54(5): 568-574. https://doi.org/10.1016/j.comppsych.2012.12.001

19. Mishlove M, Chapman LJ. Social anhedonia in the prediction of psychosis proneness. Journal of Abnormal Psychology. 1985;94(3):384-396.

20. Gooding DC, Padrutt ER, Pflum MJ. The predictive value of the NEO-FFI items: parsing the nature of social anhedonia using the Revised Social Anhedonia Scale and the ACIPS. Frontiers in Psychology. 2017;8:147. https://doi.org/10.3389/fpsyg.2017.00147

21. Bambini V, Arcara G, Bechi M, Buonocore M, Cavallaro R, Bos $\mathrm{M}$. The communicative impairment as a core feature of schizophrenia: frequency of pragmatic deficit, cognitive substrates, and relation with quality of life. Comprehensive Psychiatry. 2016;71:106-120.

https://doi.org/10.1016/j.comppsych.2016.08.012

22. Sparks A, McDonald S, Lino B, O'Donnell M, Green MJ. Social cognition, empathy and functional outcome in schizophrenia. Schizophrenia Research. 2010;122(1-3):172-178. https://doi.org/10.1016/j.schres.2010.06.011

23. Braun S, Rosseel Y, Kempenaers C, Loas G, Linkowski P. Selfreport of empathy: a shortened French adaptation of the Interpersonal Reactivity Index (IRI) using two large Belgian samples. Psychological Reports. 2015;117(3):735-753.

https://doi.org/10.2466/08.02.PR0.117c23z6

24. Chiang SK, Hua MS, Tam WCC, Chao JK, Shiah YJ. Developing an alternative Chinese version of the Interpersonal Reactivity Index for normal population and patients with schizophrenia in Taiwan. Brain Impairment. 2014;15(2):120-131.

https://doi.org/10.1017/BrImp.2014.15

25. Engel M, Lincoln TM. Concordance of self-and observer-rated motivation and pleasure in patients with negative symptoms and healthy controls. Psychiatry Research. 2017;247:1-5. https://doi.org/10.1016/j.psychres.2016.11.013

26. McCarthy JM, Treadway MT, Bennett ME, Blanchard JJ. Inefficient effort allocation and negative symptoms in individuals with schizophrenia. Schizophrenia Research. 2016;170(2-3):278284. https://doi.org/10.1016/j.schres.2015.12.017

27. Kim MK, Kim ES, Lee JS, Kim EJ, Kim J, Kim JJ. Relationship between evaluation for the self and others and anhedonia in 
patients with schizophrenia. Korean Journal of Schizophrenia Research. 2014;17(1):36-42.

https://doi.org/10.16946/kjsr.2014.17.1.36

28. Blanchard JL, Horan WP, Brown SA. Diagnostic differences in social anhedonia: a longitudinal study of schizophrenia and major depressive disorder. Journal of Abnormal Psychology. 2001;110(3):363-371.

https://doi.org/10.1037/0021-843X.110.3.363 